\title{
Analysis on Dynamic Management and Control of Construction Project Cost
}

\author{
Dan Song \\ Guangan Vocational \& Technical College, Guangan, Sichuan, 638000
}

Keywords: Construction Project Cost, Dynamic Management and Control

\begin{abstract}
Construction project cost management is the basis of cost control for construction enterprises in modern engineering, and the key point to realize the cost management of investment and construction enterprises. It is the key to bringing economic benefits and long-term profitability of construction engineering enterprises. In view of the status quo of engineering cost management in modern construction engineering construction enterprises, modern construction engineering construction enterprises should guide the construction cost management with dynamic engineering cost management theory in order to achieve the ultimate goal of engineering cost management. Now, on the modern construction project cost management and control, the paper makes a brief discussion and analysis so as to provide some references for construction companies.
\end{abstract}

\section{Introduction}

Cost management and control is an important part of the construction process, which can reduce the cost of construction projects and also promote the rationality and effectiveness of the funds in the construction process. With the acceleration of the modernization process, urban infrastructure construction has been continuously improved and the development pattern of construction projects has been more active. Construction project construction enterprises to adopt the correct way for construction project cost management, to achieve the optimal efficiency. With the rapid development of construction industry, dynamic management has gradually become the mainstream of construction cost management. The dynamic cost management has got rid of the rigid situation in the traditional cost management process and made construction cost management more flexible and pertinent, which is beneficial to improve the profitability of project construction units, reduce the capital waste and improve the comprehensive development ability of construction enterprises [1].

\section{The concept of construction project cost management and dynamic control}

The effective construction cost is a prerequisite for smooth construction and completion of construction work. It is also a key element of the entire construction work to reduce investment costs and increase economic efficiency. Therefore, we must not ignore the necessity and importance of construction cost management. Scientific, theoretical and practical aspects are the three major characteristics of construction project cost management. To carry out the dynamic cost management requires high level of professional knowledge, practical experience and technical environment. At the same time, we must abide by the relevant laws and regulations of our country. The dynamic management and control of the cost of construction projects mean that all activities in the process of work must be in line with the current situation of the society, and then carry out project cost in a scientific and reasonable way and bring about some coordination with the actual situation. To achieve the quality management and control indicators. Cost refers to the cost of the overall construction project costs, including the initial geological exploration to the latter part of the formal construction, project cost somewhat affected by subcontractors, general contractors and design units. Because the construction project in the process of construction, the cost of change is relatively large, and dynamic management and control is to stabilize the construction cost, reduce the cost of changes on the construction cost impact. Compared with the traditional control methods, the dynamic management and control of construction cost more can contact with the actual development, not only can effectively control the uncertainties and instabilities in the process of 
construction cost, but also can further accelerate the pace of construction and more Able to fully coordinate the relationship between construction cost and economic benefits.

\section{The link in construction project dynamic management}

In the decision-making stage, we must first make a comprehensive assessment of the factors that affect the construction cost, and conduct dynamic management and control based on the assessment data and formulate the best investment feasibility plan. After carrying out the feasibility study of the project, the overall price of the construction project should be determined and a reasonable project scale should be determined [2]. At the same time, various influencing factors should be analyzed. At present, some construction projects are only pursuing economies of scale rather than pursuing economies of scale. The most prominent feature of these projects is that they do not need to carry out economic assessments. The economic benefits of the project will therefore be reduced linearly. At the same time, this will also affect the overall social benefits. All construction projects should be based on the most basic principle is that as far as possible the construction site near the origin of construction materials, but also to ensure the quality of the traffic around the construction site. This can greatly reduce the cost of transportation of construction materials, but also reduce the time of arrival of materials, the construction progress of the construction and economic circulation are of great help.

The preliminary design stage is the most influential stage of the project cost, but also the most important aspect of the entire design stage. Therefore, at this stage, the architects should take full responsibility for the design plan, but also the construction cost and engineering design these two elements fully integrated, and then conduct a scientific analysis of its final formulation of the best Design program, and the project cost control work closely.

This stage is mainly the preparation of the basic design and bidding documents, according to the relevant survey report shows that the impact of technical design on the construction cost of the project accounted for $76 \%$. The scientific design of the construction drawings is an effective prerequisite for the construction budget, bidding and bidding, signing the construction contract and compiling the construction schedule, and is also an important basis for the acceptance of the construction project completion and settlement. Therefore, when drawing the construction drawings, designers should conduct a scientific analysis of the surrounding environment of the construction site, carefully consider the various factors that affect the progress of the project, and make reference to some completed data files and design according to the construction details. Try to minimize the potential for increased costs due to project leaks, design changes, and more.

\section{The status quo of construction cost of dynamic management and control}

Project cost is a prerequisite for saving funds and improving the work plan. It is also an expression of cost investors' control and management of costs in construction projects. Based on the existing market environment, it can be said that the level of construction cost directly affects the result of bidding for construction in progress, which can be an important factor for investors to measure the technical level of a construction enterprise. During the bidding process, investors value the construction concept, technical level and control ability of construction engineering enterprises very much, whether they can do the dynamic management and control of construction cost and the quality of their work. In recent years, the construction industry in the market economy has made a qualitative leap in the speed of development, and the quality of the cost management of construction companies has gradually become the basic factor that affects the continuous development of construction units in the industry competition. According to the relevant survey report shows that the author's practical experience shows that the management and control of construction cost can better control the construction cycle, quality and cost of the relationship between the construction work for the post-costing work laid a solid foundation [3]. However, from a practical point of view, in the fierce market competition, the majority of construction enterprises in the dynamic management mode and control measures are more or less loopholes, the main reason is that in this 
area lack of appropriate experience, the final building The quality of project cost management will inevitably be affected, therefore, the problems in this respect must be properly solved.

\section{Measures in construction project cost of dynamic management and control}

Before the project is officially started, the cost management staff should have a clear understanding of the cost management and then fundamentally realize the cost management and control. Involved in the bidding process cost management factors are more, cost personnel should be combined with the specific project conditions, the bill of quantities scientific and reasonable preparation, from the fundamental to ensure that the contract price of science and rationality to ensure its actual market background Match. In the process of calibration and decision-making, it is necessary to take the bill of quantities as the judgment basis and standard to maximize the scientific and normative work of bidding and tendering. Bidders should have a clear understanding of the specific bidding system and awareness in order to improve the quality and effectiveness of bidding and bidding to achieve a good bidding effect, the construction cost to a minimum [4].

In the design stage, the design plan is the main factor affecting the construction project cost control. Cost personnel should be combined with the specific construction project, the design of scientific and reasonable selection to ensure that the design and construction of the actual situation to match, and to ensure that the design of the economy and practicality. At the same time, we must also carry out a rigorous examination of the relevant investment categories in the design plan and conduct rigorous examination and discussion on the investment uncertainty areas so as to ensure that the cost control in the design stage is reasonable and the accuracy of the investment. In the design plan, we should also understand and analyze the performance, use, quality and price of the materials and equipment involved in the construction project in detail. Based on the specific project conditions and the overall quality of the construction project, the construction project will be maximally saved The purchase cost. The person in charge of construction should also make scientific and reasonable selection of construction technology and construction plan according to the demands of actual construction projects and the specific conditions at the construction site so as to ensure the rationality of the construction schemes and technical elements and then make use of the high quality of the design links to realize the construction cost control. Construction drawings should not only involve the overall layout and planning of construction projects, but also clearly stipulate the materials and equipment involved in construction so as to effectively avoid engineering changes caused by unreasonable construction, thereby increasing the construction cost and the overall construction cost [5].

Construction stage is directly related to the overall funding of construction projects. Cost control staff to clearly define the cost, and continue to raise awareness of cost control of the management staff, to minimize unnecessary waste of funds, and dynamic construction project cost management put in place. Construction of the construction period is relatively long, the construction process involved materials, equipment, personnel, etc. by the dynamic construction market, there are many uncertainties. In the process of cost management, the dynamic factors such as market price volatility should be pre-analyzed and analyzed to ensure the flexibility and dynamic control of construction project cost control. Cost management personnel should make clear analysis on the relevant changes during the construction of the construction process, and strictly examine the material changes and technical changes, and then summarize and analyze the changes in the budget prices involved. For construction projects in the process of capital changes, a rigorous examination to ensure that the regulatory process of normative. At the same time, construction must also be carried out in accordance with the specific construction requirements to avoid unnecessary waste in the construction process. And strictly follow the contract to carry out the construction, timely changes to deal with the contract.

\section{Conclusions}

With the continuous construction and development of social economy in our country and the 
continuous deepening of the reforming system, the economic system with Chinese characteristics is being established. This has a significant impact on China's construction industry and also leads the construction industry to a new height. Not only formed the two relative interests of construction and construction, but also taken new steps in the scientific aspects of construction cost, basically determined the management and control system of construction cost, and put it into practical work.

\section{References}

[1] Tan Guangmin. Engineering cost management issues and Countermeasures [J]. Urban Construction Theory Research (Electronic Version), 2014 (8): 18.

[2] Liu Yujuan. Construction project cost management problems and countermeasures [J]. New Materials and New Decoration, 2014 (9): 540 - 540.

[3] Wu Lihua. Project cost management problems and countermeasures [J]. Liaoning Economy, 2010 (5): 86.

[4] Yan Yifan. Project cost management problems and countermeasures [J]. Heilongjiang Water Conservancy Technology, 2011 (4): 189 - 190.

[5] Xie Zheng, Mo Lianguang. Project cost management problems and countermeasures [J]. Heilongjiang Science and Technology Information, 2010 (35): 111. 